Catherine Rannoux, Les fictions du journal littéraire. Paul Léautaud, Jean Malaquais, Renaud Camus

\title{
Emanuele Kanceff
}

\section{(2) OpenEdition}

1 Journals

\section{Edizione digitale}

URL: http://journals.openedition.org/studifrancesi/36563

DOI: 10.4000/studifrancesi.36563

ISSN: 2421-5856

\section{Editore}

Rosenberg \& Sellier

\section{Edizione cartacea}

Data di pubblicazione: 1 juillet 2005

Paginazione: 193

ISSN: 0039-2944

\section{Notizia bibliografica digitale}

Emanuele Kanceff, «Catherine Rannoux, Les fictions du journal littéraire. Paul Léautaud, Jean Malaquais, Renaud Camus», Studi Francesi [Online], 145 (XLIX | I) | 2005, online dal 30 novembre 2015, consultato il 18 avril 2021. URL: http://journals.openedition.org/studifrancesi/36563 ; DOI: https://doi.org/10.4000/ studifrancesi.36563

Questo documento è stato generato automaticamente il 18 avril 2021.

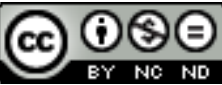

Studi Francesi è distribuita con Licenza Creative Commons Attribuzione - Non commerciale - Non opere derivate 4.0 Internazionale. 


\title{
Catherine Rannoux, Les fictions du journal littéraire. Paul Léautaud, Jean Malaquais, Renaud Camus
}

\author{
Emanuele Kanceff
}

\section{NOTIZIA}

CATHERINE RANNOUX, Les fictions du journal littéraire. Paul Léautaud, Jean Malaquais, Renaud Camus, Genève, Droz, 2004, pp. 216.

1 In una densa introduzione, Catherine Rannoux esamina lo statuto del diario letterario così come la letteratura del Novecento lo ha ereditato dai secoli precedenti e lo ha praticato; statuto ambiguo, che oscilla tra scrittura intima e reportage oggettivo, tra introspezione e finzione, sì che l'unica costante della vasta gamma di «prodotti» che ne deriva può essere individuata nella scrittura temporale discontinua. Anche i legami tra il genere e il campo letterario si rivelano di complessità crescente: il diario dello scrittore, composto nell'intimità, luogo di una scrittura che dovrebbe essere immediata, è in realtà oggetto di correzioni e rifacimenti multipli così come lo sono tutte le opere letterarie e, non destinato in effetti ad una pubblicazione immediata, il diario dello scrittore segue un iter parallelo e del tutto simile a quello delle altre opere. Se acquisisce dapprima una posizione di semi-ufficialità per la sua posizione che lo pone al di sopra e in osservazione dell'opera, con la pubblicazione diventa soltanto un altro modo di fare della letteratura.

2 L'autrice ha scelto di privilegiare tre opere e tre scrittori appartenenti a tre generazioni differenti: Paul Léautaud e il suo diario letterario che spazia dal 1893 alla morte dello scrittore nel 1956, in più di seimila pagine, ma di cui non si considera in questo studio che la parte tra il 1939 e il 1942, al fine di un discorso critico parallelo con quello che rivolge l'attenzione ad un altro diarista esemplare, l'ebreo polacco Jean Malaquais, che redige il suo diario tra il 1939 e il 1942 come diario di guerra e poi di un meticcio. Il 
terzo diario preso a campione ci conduce invece fuori dei nostri limiti cronologici e forse anche ideali: Feindre l'air. Journal 1989, di Renaud Camus, differisce infatti dai due precedenti sia per le date sia per le circostanze della scrittura. Tuttavia, l'autrice giustifica la sua scelta con il ratio che anche questo diario è scritto in condizioni storiche eccezionali (la caduta del muro di Berlino, il crollo dei regimi dell'Europa orientale, la rivolta degli studenti in Cina) che permettono un confronto non limitato alla scrittura dell'io. 